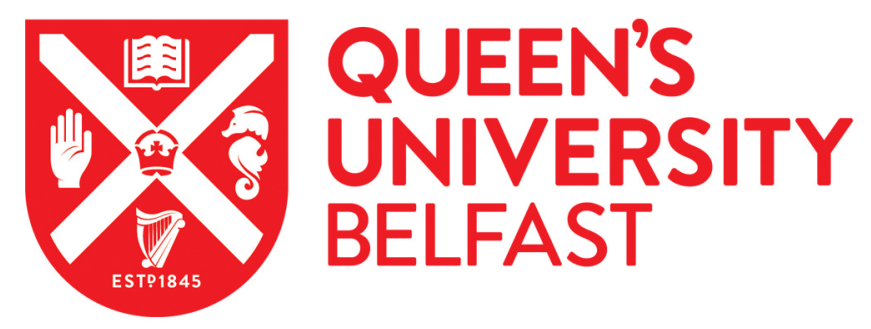

\title{
Emotional Insecurity about the Community: A Dynamic, Within-Person Mediator of Child Adjustment in Contexts of Political Violence
}

Cummings, E. M., Merrilees, C. E., Taylor, L. C., Goeke-Morey, M., \& Shirlow, P. (2017). Emotional Insecurity about the Community: A Dynamic, Within-Person Mediator of Child Adjustment in Contexts of Political Violence. Development and Psychopathology, 29(1), 27-36. https://doi.org/10.1017/S0954579416001097

\section{Published in:}

Development and Psychopathology

\section{Document Version:}

Peer reviewed version

Queen's University Belfast - Research Portal:

Link to publication record in Queen's University Belfast Research Portal

\section{Publisher rights}

This article has been published in a revised form in Development and Psychopathology https://doi.org/10.1017/S0954579416001097. This version is free to view and download for private research and study only. Not for re-distribution, re-sale or use in derivative works. \# Cambridge University Press 2016

\section{General rights}

Copyright for the publications made accessible via the Queen's University Belfast Research Portal is retained by the author(s) and / or other copyright owners and it is a condition of accessing these publications that users recognise and abide by the legal requirements associated with these rights.

Take down policy

The Research Portal is Queen's institutional repository that provides access to Queen's research output. Every effort has been made to ensure that content in the Research Portal does not infringe any person's rights, or applicable UK laws. If you discover content in the Research Portal that you believe breaches copyright or violates any law, please contact openaccess@qub.ac.uk. 
Running Head: EMOTIONAL INSECURITY ABOUT COMMUNITY

\author{
Emotional Insecurity about the Community: A Dynamic, Within-Person Mediator of \\ Child Adjustment in Contexts of Political Violence
}

\author{
E. Mark Cummings \\ University of Notre Dame \\ Christine Merrilees \\ State University of New York, Geneseo \\ Laura K. Taylor \\ Queens University, Belfast \\ Marcie Goeke-Morey \\ Catholic University of America \\ Peter Shirlow \\ Queens University, Belfast
}




\begin{abstract}
Background: Over one billion children worldwide are exposed to political violence and armed conflict. Currently, conclusions are qualified by limited longitudinal research testing sophisticated process-oriented explanatory models for child adjustment outcomes. In this study, consistent with a developmental psychopathology perspective emphasizing the value of processoriented longitudinal study of child adjustment in developmental and social-ecological contexts, we tested emotional insecurity about the community as a dynamic, within-person mediating process for relations between sectarian community violence and child adjustment. Specifically, this study explored children’s emotional insecurity at a person- oriented level of analysis assessed over five consecutive years, with child gender examined as a moderator of indirect effects between sectarian community violence and child adjustment. Methods: In the context of a five-wave longitudinal research design, participants included 928 mother-child dyads in Belfast (453 boys and 475 girls) drawn from socially-deprived, ethnically-homogenous areas that had experienced political violence. Youth ranged in age from 10 to 20 and were $13.24(S D=1.83)$ years old on average at the initial time point. Findings: Greater insecurity about the community measured over multiple time points mediated relations between sectarian community violence and youth's total adjustment problems. The pathway from sectarian community violence to emotional insecurity about the community was moderated by child gender, with relations to emotional insecurity about the community stronger for girls than for boys. Conclusions: The results suggest that ameliorating children's insecurity about community in contexts of political violence is an important goal toward improving adolescents’ well-being and adjustment. These results are discussed in terms of their translational research implications, consistent with a developmental psychopathology model for the interface between basic and intervention research.
\end{abstract}


Keywords: Political violence, social ecology, community, mental health, emotional security, youth's total adjustment problems 


\section{Emotional Insecurity about the Community: A Dynamic, Within-person Mediator of Child Adjustment in Contexts of Political Violence}

The effect of political violence and armed conflict on youth adjustment is a matter of urgent, international concern (Masten \& Narayan, 2012). Worldwide, more than one billion children under the age of eighteen are growing up in settings of armed conflict and political violence (United Nations, 2011), with accumulating evidence to support negative implications of these contexts for children's adjustment. For example, cross-sectional associations between political violence and youth’s adjustment problems are well-established (e.g., Dubow, Huesmann, \& Boxer, 2009). However, limited progress has been made in understanding the psychological processes that underlie these relations.

Consistent with a developmental psychopathology perspective (Cicchetti, 2006), an advanced research design is presented in this manuscript for process-oriented longitudinal tests of the impact of elements of the social ecology associated with a context of political violence on child adjustment. Longitudinal tests of mediators and moderators of the development of adjustment problems are needed to advance explanatory models for how and why and for whom and when, youth are at risk for maladjustment (Cummings, Goeke-Morey, Schermerhorn, Merrilees \& Cairns, 2009). Related goals or themes include the study of developmental processes in the context of political violence and the need for complex modeling and analyses of explanatory processes, including both positive and negative developmental processes over time (Cicchetti, 2006). It is likely that multiple psychological processes contribute to child outcomes, so testing of multiple explanatory models will likely be essential to a comprehensive assessment of youth development in these contexts. Longitudinal research based on well-articulated conceptual models have only begun to appear in the literature and are an essential direction for 
advancing understanding of the etiology of youth adjustment (e.g., Betancourt, Brennan, RubinSmith, Fitzmaurice, \& Gilman, 2010; Boxer et al., 2013).

Although the majority of longitudinal studies test assess mediation at a single point in time, psychological processes affecting youth development are likely to change over time. A key principle from a developmental psychopathology perspective is that mediating processes should be viewed as dynamic and changing over time and also changing within a person, so that any single assessment may not adequately reflect a dynamic level of functioning (Cummings \& Valentino, 2015). Thus, consistent with the goals of this Special Section, this manuscript provides a tangible, empirical direction for how scholars in this area of study may be able to achieve more advanced understanding of the processes associated with the impact of political violence on child adjustment.

Along with other explanatory models that have been advanced in this literature (see also Betancourt et al., 2010; Dubow et al., 2009), Emotional Security Theory (EST, Davies \& Cummings, 1994) has been proposed as one of the theoretical models for psychological processes associated with youth adjustment in contexts of political violence (Cummings et al., 2009). According to EST, children’s adjustment and well-being are influenced by the extent to which children feel secure in multiple contexts of the social ecology (e.g., family; community; the historical political context). Accumulating research and theory support that emotional security processes are pertinent to understanding youth adjustment in the face of multiple contexts of family, community and political conflict and violence (Cummings \& Davies, 2011; Cummings et al., 2014).

Another emphasis of this Special Section is on the centrality of a social-ecological model for fully articulating the domain of contextual influences on children's development, including 
analyses of explanatory processes in social-ecological contexts, towards better understanding of key mediators and moderators that may act as risk or protective factors influencing child adjustment (Cicchetti \& Lynch, 1993; Lynch \& Cicchetti, 1998; Cicchetti \& Valentino, 2006). Traditionally, emotional security has been examined in the context of the parent-child relationship (Bowlby, 1973). However, over the past two decades this notion has been extended to include other family relationships (Cummings et al., 2012) and also contexts outside of the family (e.g., the community, Cummings et al., 2011). The implication is not that contexts outside of the family are more important than the family to emotional security but that multiple contexts need to be considered in evaluating children's emotional security in contexts of political violence. In all of these contexts emotional security is conceptualized as a goal associated with children's regulatory processes in the context of violence, conflict or other threats to their wellbeing, related to their adjustment in multiple social-ecological contexts (Cummings \& Davies, 2011). Children’s safety and security are seen as central concerns around which their functioning is regulated, including cognitive, emotional, and behavioral responses in the service of maintaining or regaining the desired sense of emotional security in a challenging or threatening context. Maladaptive patterns of adjustment develop as a function of efforts to respond over time to threats in the social ecology (e.g., conflict and violence), with the result of lowered thresholds for behavioral or emotional dysregulation or the excessive use of psychological or physical capacities to regulate or control functioning, thereby undermining capacities for using resources to accomplish adaptive psychological functioning and pursuit of developmental goals (see also the social-ecological proposed by Dubow et al., 2009) .

Northern Ireland is a relevant context for the examination of the psychological impact of political violence on youth adjustment (Cairns, 1996). In Northern Ireland, sectarian (politically- 
related) violence has traditionally occurred between the two primary social groups: Catholics and Protestants. Although some would argue this conflict has existed for several centuries, recent research has focused on the 30-year period of violence between 1968 and 1998, identified as the “Troubles” (Cairns \& Darby, 1998). Despite the fact that a peace accord was reached in 1998, sectarian violence has continued, especially in socially-deprived communities and neighborhoods in Belfast (see Police Service of Northern Ireland, Central Statistics Branch, Operational Support Department, 2013).

With regard to support for mediational models explaining youth adjustment, within the current context of political violence in Northern Ireland, Cummings et al. (2011) reported in a three-wave model test that emotional insecurity about the community mediated links between youth exposure to political violence and adjustment problems. However, this longitudinal test of emotional insecurity as an explanatory process mediating relations between ecological contexts of political violence and youth adjustment was based on (a) emotional insecurity about the community assessed at a single point in time and (b) a between-persons test of the mediating role of emotional insecurity about the community. Notably, the present study breaks new ground by examining emotional insecurity about the community (Cummings et al., 2011) as a mediating process characterized as a within-person process.

Relatedly, consistent with a purpose of this Special Section to advocate research designs for more advanced study of developmental process in the context of children and political violence and armed conflict (Cicchetti, 2006; Cicchetti \& Cohen, 1995), by employing five waves of longitudinal data in assessing emotional insecurity about community as a mediator, this study also advances the examination of mediators as within-person influences over time, thereby also contributing to the study of mediating processes from a person-oriented perspective (Sterba 
\& Bauer, 2010). Person-oriented research emphasizes the study of intra-individual variability in the context of change over time (Nesselroade \& Molenaar, 2010). Although person-oriented approaches have traditionally emphasized classification methods, approaches that model individual or within-person changes over time in studying explanatory processes are increasingly seen as an important direction for studying person-oriented conceptualizations of change (Sterba \& Bauer, 2010). These approaches may be especially informative for intervention directions given that change during human development ultimately occurs at the level of the individual. Charting intra-individual trajectories of mediating processes has the potential to advance understanding of developmental processes contributing to youth risk and resilience from a person-oriented perspective (Bergman, von Eye, \& Magnusson, 2006; Cummings \& Valentino, 2015).

That is, the between-person mediational effects documented in past research (Cummings et al., 2011) suggest that youth who are exposed to higher levels of sectarian antisocial behavior are more likely to develop adjustment problems compared to youth who are exposed to lower levels of sectarian antisocial behavior because they are more likely to develop a sense of insecurity in the community compared to the less exposed youth. This between-person mediation makes comparisons across the sample. On the other hand, within-person mediation allows for the detection of how change occurs relative to that individual's own baseline measures. For example, do higher levels of exposure (compared to an individual's baseline exposure) to sectarian antisocial behavior predict higher levels of insecurity in the community relative to that individual's baseline? In turn, do the elevated levels of insecurity relate to more adjustment problems from a given person’s baseline? 
From a developmental psychopathology perspective, the identification of risk and protective factors at a process-oriented level in developmental and social-ecological contexts suggests especially important targets for intervention, that is, bases for the translation of basic research findings into elements of intervention programs (Cicchetti \& Toth, 2006). With regard to this point, tests of within-person mediation provides advances over previous longitudinal tests based on between-person mediation by focusing on mediational processes at the level at which individual change occurs, that is, a person-oriented level of analysis. Accordingly, the identification of mediational processes at this level of analysis may hold particular promise for translation of basic research findings into more efficacious interventions (Cummings \& Valentino, 2015).

In addition, child gender in the present study is examined as a potential moderator of these relations when emotional security is measured as a within-person mediator. In some instances child gender has been found to moderate models for the processes mediating the effects of violence in the broader social ecology on child adjustment. For example, Cummings, Davies, and Simpson (1994) found the threat posed by marital conflict was more closely linked with adjustment problems in boys, but self-blame was more linked with adjustment problems in girls. Cummings et al. (2011) did not identify child gender as moderator of relations between sectarian community violence and emotional insecurity; however, the statistical approach in this instance was based on a between-person test of the mediator (Bollen, 1989). Although both boys' and girls’ adjustment is influenced by emotional security, some studies have found that girls report higher insecurity and the relationship between insecurity and adjustment is stronger for girls (Davies, Forman, Rasi, \& Stevens, 2002); person-oriented analyses may be more sensitive than between-person tests to gender differences as a moderator of these relations. 
In summary, a hallmark of the next generation of research on political violence, armed conflict, and child adjustment, consistent with a developmental psychopathology perspective, and reflected in the empirical and other contributions of this Special Section, is the conduct of longitudinal studies that embody a process-oriented, social-ecological perspective (Cicchetti, 2006; Cicchetti \& Lynch, 1993). The present study utilizes five waves of longitudinal data to examine a model for theory-based mediating process (emotional insecurity in the community) as within-person mediators of child adjustment. Further reflecting a process-oriented perspective, a moderator of mediation (i.e., child gender) is examined in terms of predicting specific pathways in the test of the mediational model.

\section{Method}

\section{Participants}

Participants included ( $\mathrm{N}=928)$ adolescents who participated in at least one wave of waves two through six of a longitudinal study in Belfast, Northern Ireland. Adolescents' mean age was 13.24 ( $S D=1.83), 13.61(S D=1.99), 14.66$ years $(S D=1.96), 15.75(S D=1.97)$ and 16.83 $(S D=1.99)$ across the five time points. Youth were approximately evenly divided between girls and boys ( 453 boys and 475 girls). At the outset of the study, youth lived in families in which $42 \%$ of mothers were married or living as married ( $n=571)$ and $58 \%$ were in single-parent households ( $n=413$ ) including being separated, divorced, widowed, or having never married. Sixty-two percent of participants identified as being Protestant, and 37\% as Catholic.

Across waves retention was approximately $80 \%$ of the sample from the previous time

point. This rate of retention is at the higher end of the range of retention reported for comparable high-risk, longitudinal samples, with retention rates in these studies ranging from $50 \%$ to $86 \%$ 
(e.g., Betancourt et al., 2010; Browning, Burrington, Leventhal, \& Brooks-Gunn, 2008;

Kronenberg et al., 2010). Of the original sample of 695 mother-child dyads beginning participation at time $1,82 \%$ returned at time $2(n=572), 67 \%(n=466)$ at time 3 , and $61 \%$ $(n=422)$ at time $4,61 \%(n=425)$ at time 5 , and 64\% $(n=447)$ at time 6 (more families from earlier waves participated in wave 6 than in wave 5). Data for the current study included all families participating in waves 2-6. A supplemental set of families living in the original study areas was added to the longitudinal study at wave 3 . The goal of the supplement was to have relatively similar distributions of families across neighborhoods at the outset of the study and to replenish the sample size lost from attrition; thus, recruitment of new families over-sampled relatively higher-risk neighborhoods characterized by greater attrition.

\section{Procedures}

The original study areas were selected to obtain a representative sample of Catholics and Protestants and variation in levels of sectarian violence (see Cummings, Schermerhorn et al., 2010). A demographer expert in the ethnic, social, historical, and economic characteristics of Belfast identified neighborhoods varying in both historical and current politically-motivated, sectarian violence. He also chose neighborhoods in the lowest quartile of social and economic deprivation based on the Multiple Deprivation Rank (MDR). The MDR is a ranking of all 582 wards in Northern Ireland and it uses income, employment, health, education, proximity to services, crime, and the quality of the living environment to determine an overall deprivation rank (NISRA, 2011). Consistent with the segregated nature of life in Belfast (Shirlow \& Murtagh, 2006), the majority of study participants lived in wards that were ethnically homogenous (over 90\% Catholic or Protestant; NISRA, 2011) and interfaced, or sharing a border, with neighborhoods predominantly populated by the other group. Families in the current 
study live segregated lives (Cairns \& Toner, 1993; Shirlow \& Murtagh, 2006), reflected in the separation of Catholics and Protestants in marital, educational, and professional relationships (Hughes et al., 2007).

Thirty-five to 40 families participated per neighborhood. A family was eligible to participate if there was a child between the ages of 10 and 17 years old living in the home, although a small number of families with slightly younger children were allowed to participate. For families with two or more children within the indicated age range, the youngest interested child participated. This age period was selected because children and adolescents in the target age range (a) have been shown to be aware of the social distinctions relevant to the study (Catholic / Protestant differences; Cairns, 1987) and (b) are likely to be informed about or exposed to sectarian and nonsectarian violence, as observers, victims, or participants. Families added at time 3 were identified and recruited following the same procedures within the same study areas as for the original sample at time 1.

Given the close-knit nature of these communities, community leaders were first identified by the demographer expert in these areas of Belfast, and letters were sent to these community leaders informing them that we planned to contact families in their communities concerning participation in a research study of political violence, community, and family relationships and child development. Next, letters with the same description of the study were sent to families inviting them to participate. Families were then contacted by phone or engaged door-to-door, consistent with local custom in Belfast. Professional interviewers from an established market research firm conducted in-home surveys with youth, which lasted approximately 30 minutes. The confidential and voluntary nature of the study was emphasized. Interviewers were frequently from these neighborhoods or similar neighborhoods, which facilitated rapport building with 
participants. Before participating, mothers and children provided consent and assent, respectively; families received $£ 20$ at times 1 and 2, $£ 40$ at times 3 and 4 , and $£ 50$ at times 5 and 6 for their participation. The research protocol and measures were approved by the Institutional Review Boards at all participating universities.

\section{Measures}

Sectarian Antisocial Behavior (SAB and NAB). This scale assessed adolescents' awareness of sectarian antisocial behaviors in their communities. The measure was developed specifically for the context of Belfast, and distinguishes between political and everyday crime in contemporary Northern Ireland. Focus groups with mothers living in Belfast revealed that individuals living in these areas clearly distinguished between sectarian and nonsectarian threats to their communities (Taylor et al., 2011). Scales were developed and tested in a pilot project with mothers in Derry/Londonderry to establish the psychometric properties of these measures (see Goeke-Morey et al., 2009, for report of instrument development).

In the current analyses, child-report versions of the scale were used. Using a 5-point scale (0 (not in the last 3 months), 1 (once in the last 3 months), 2 (every month), 3 (every week), to 4 (every day) youth reported on how frequently in the last three months a series of items occurred.

The instructions were: "This set of questions is about your community. For these next questions, your community refers to the [insert denominational community participant identified earlier] community. And the OTHER community refers to the [insert other] community. These next questions are about things that might happen in your community. Please report only events that actually occurred in the community, not incidents from movies or fictional television” (page 841, Cummings, Schermerhorn et al., 2010). 
For the 12-item sectarian antisocial behavior scale (SAB), items included stones or objects thrown over walls, name calling by people from the other community, and deaths or serious injury caused by the other community (see Cummings, Schermerhorn et al., 2010, for the complete scale). Good internal consistencies for each scale were obtained across all four time points of the present study (Cronbach's $\alpha$ were .95, .96, .98, .94, and .91for SAB for times 2, 3, 4, 5 and 6, respectively).

Insecurity in the Community. Adolescents completed the seven-item Security in the Community questionnaire (SIC). The SIC assesses the adolescent's sense of safety and threat about the community, sensitive to the cultural context of Northern Ireland. Items were scaled such that high scores indicated greater insecurity about the community. Example items are "I feel scared when people from the other community walk toward me," and "I worry that bad things will happen in my community.” Youth responded to statements using a 5-point Likert-type scale ranging from (1) Not at all like me (5) A whole lot like me. Focus groups and pilot work with independent samples supported instrument development and demonstrated adequate psychometric properties, including internal consistency and predictive and construct validity (Goeke-Morey et al. 2009 ). Cronbach’s alpha for this scale was 0.82, .86, .85, .82, and .74 across the six waves.

Child Adjustment Problems. Total youth adjustment problems were assessed with the youth report on the Strengths and Difficulties Questionnaire (SDQ; Goodman, 1997).

Psychometric properties of the SDQ are well established in UK samples and are preferable to the Child Behavior Checklist (CBCL; Achenbach, 1991) for community samples for predicting adjustment problems (Goodman \& Scott, 1999). The Total Problems scale consists of 20 items, five questions for each of four subscales: Emotional Problems (e.g., many worries, often seems 
worried); Peer Problems (e.g., often fights with other children or bullies them); Hyperactivity (e.g., restless, overactive, cannot stay still for long); and Conduct Problems (e.g., steals from home, school, or elsewhere), respectively. Higher scores represent more adjustment problems. Good internal consistencies were found across all 5 waves (Cronbach's $\alpha=.76, .73, .73, .76$, and .66). The Total Behavior Problems scale was used to provide an assessment of overall youth adjustment, which was the interest in this report, and also has an advantage of higher internal consistency than specific subscales of behavior problems (Goodman, 1997).

\section{Results}

\section{Overview of Analyses}

Means and standard deviations for all study variables at each age are shown in Table \#. All data were modeled using a multilevel modeling approach. A multilevel modeling approach was used to account for the dependence in the repeated measures data. Multilevel modeling is a preferred method of analyzing nested data such as repeated measures data or data clustered within communities or schools as it can accommodate the dependency of the data. More specifically, separate equations are specified for both the within- and between-person levels of the data. This approach allows for the study of inter-individual differences in intra-individual change. For the within-person variables at Level 1, the outcome variable is regressed on withinperson predictors such as time and other time-varying factors in the data (i.e., time-varying covariates). The Level 1 parameters are then used as outcome variables regressed on Level 2 predictors. An additional advantage of multilevel modeling is that maximum likelihood estimation accurately estimates parameters with missing data, assuming that data are missing at random. 
For the current paper, to test for within-person mediation and the value of the indirect effect for the level one model of mediation, we followed procedures described by Bauer, Preacher, and Gil (2006). Specifically, we tested 1-1-1 mediation where all variables are nested in level 1. All analyses were conducted using Hierarchical Linear Modeling software (version 6.06; Radenbush, Bryk, Cheong, \& Congdon, 2004). For the current model, the cross-sectional within-person mediation is estimated for each person based on his/her five waves of data. In order for this form of estimation to work, the data files must be constructed with dummy variables. This approach allows HLM to recognize “y” as two predicted variables, that is, both the mediator and the outcome (see example in Bauer et al., 2006). Change over time is not modeled, nor are lagged, auto-regressive effects, due to the number of predictors in the model. The elaborated model includes dummy variables that indicate whether the parameter to be estimated is predicting the mediator (i.e., emotional insecurity) or the outcome (i.e., adjustment problems). The use of the dummy variable in this way allows for estimation of all three relevant paths (i.e., predictor to mediator, predictor to outcome, mediator to outcome) in the same model. In the model below, the dummy variables $\mathrm{S}_{\mathrm{M}}$ and $\mathrm{S}_{\mathrm{Y}}$ are used to allow $\mathrm{Z}$ to take on both the value of the mediator emotional security and the outcome total problems. The full model is below.

$$
Z=d_{M j} S_{M j}+a_{j}\left(S_{M j} X_{i j}\right)+d_{Y j} S_{Y i j}+b\left(S_{Y i j} M_{i j}\right)+c^{\prime}{ }_{j}\left(S_{Y i j} X_{i j}\right)+e_{Z i j}
$$

When $\mathrm{Z}$ represents emotional insecurity, $\mathrm{S}_{\mathrm{M}}$ takes on the value of 1 and Sy takes on the value of 0 , dropping out three terms in the above equation and reducing the equation to

$$
\mathrm{Z}=\mathrm{d}_{\mathrm{Mj}}+\mathrm{a}_{\mathrm{j}} \mathrm{X}_{\mathrm{ij}}+\mathrm{e}_{\mathrm{Zij}}
$$

representing the effect of SAB on emotional insecurity. In this model $\mathrm{d}_{\mathrm{Mj}}$ represents the intercept, or average value of emotional insecurity for a given person, and $a_{j} X_{i j}$ represents the effect of 
SAB on insecurity. When Z represents total problems, Sy takes on the value of 1 and SM takes on the value of 0 , dropping out two terms in the equation reducing the equation to

$$
\mathrm{Z}=\mathrm{d}_{\mathrm{Yj}}+\mathrm{bM}_{\mathrm{ij})}+\mathrm{c}_{\mathrm{j}} \mathrm{X}_{\mathrm{ij})}+\mathrm{e}_{\mathrm{Zij}}
$$

representing the effects $\mathrm{SAB}$ and emotional insecurity on total problems. In this equation $\mathrm{d}_{\mathrm{Yj}}$ represents the intercept, or average value of total problems, $\mathrm{bM}_{\mathrm{ij}}$ represents the effect of emotional insecurity on total problems, and c' ${ }_{j} \mathrm{X}_{\mathrm{ij}}$ represents the effect of SAB on total problems.

The results from this model indicate that higher exposure to sectarian antisocial behavior predicts higher insecurity scores $(\gamma=.27, S E=.02, p<.001)$, and higher insecurity predicts higher total problems $(\gamma=.16, S E=.03, p<.001)$. Results also show a direct effect of exposure to sectarian antisocial behavior on total problems $(\gamma=.12, S E=.02, p<.001)$. Estimates of the variance components shows that there is significant variability in all three paths (SAB predicting Insecurity: .06, $p<.001$; Insecurity predicting Adjustment Problems: .11, $p<.001$; SAB predicting Adjustment Problems: .02, $p<.001$ ). To test the value of the indirect effect, parameter and variance estimates were entered in a macro that estimated the indirect and total effects and their 95\% confidence intervals. The results suggest the value of the indirect effect is significant (.06: 95\% CI $(.03, .10))$. The total effect was .18 (95\% CI: .13, .24). In summary, the above analyses suggest that using multiple waves of cross-sectional data, the effect of exposure to SAB on total behavior problems is at least partially explained by emotional insecurity in the community. Previous between-person tests suggested that, compared to those exposed to less sectarian antisocial behavior, those individuals exposed to higher antisocial behavior are more likely to report higher emotional insecurity compared to others in the sample. The current analysis take this a step further; compared to one's own average exposure, when individual exposure is higher than the person-specific average, that adolescent is more likely to report a 
higher than self-average of insecurity and a higher than self-average of total problems. In essence, the relevant comparison is for the youth himself or herself, rather than compared to peers. This approach furthers the person-specific understanding of how emotional security functions during development.

\section{Gender Differences}

To examine gender differences in these within-person processes, we next ran a conditional model with gender predicting the variance in intercepts and the a, b, and c paths. Gender was a significant predictor of the intercept for security $(\gamma=.39, S E=.17, p<=.024)$ suggesting that girls reported higher insecurity compared to boys. Gender also significantly predicted variance in the relation between exposure to sectarian antisocial behavior and insecurity $(\gamma=.09, S E=.04, p=.013)$, suggesting a stronger relationship between SAB and insecurity for girls. No other significant gender differences emerged (i.e., the path from SAB to adjustment or the path from insecurity to adjustment).

\section{Discussion}

The present findings support the proposition that emotional insecurity about the community affects youth’s risk for total adjustment problems in contexts of political violence. Building on evidence that emotional insecurity about the community contributes to interindividual differences in mediating relations between sectarian community violence and children’s adjustment problems in Northern Ireland (Cummings et al., 2011), intra-individual emotional insecurity about the community over multiple time points was also identified as related to children’s total adjustment problems. Moreover, girls evidenced greater insecurity about the community and stronger relations were found between sectarian community violence and emotional insecurity about the community for girls than for boys. This report thus (a) affirms 
emotional insecurity about the community assessed as within-person process that mediates relations between sectarian community violence and the development of adjustment problems and (b) demonstrates that insecurity about community is more strongly affected by sectarian community violence for girls than for boys.

Specifically, the results of tests for mediation at level 1 provided evidence for a significant within-person indirect effect of emotional insecurity in the community (SIC) in mediating the effects of sectarian antisocial behavior (SAB) on youth total adjustment problems (see Figure 1). Modeling mediation with random effects modeling allowed for the direct prediction of variability in these processes. Moreover, adding gender at level 2 showed that the relation between SAB and SIC was stronger for girls compared to boys (see Figure 2). That is, the present analyses found between gender differences in the link between exposure to sectarian antisocial behavior and youth's security in the community.

Previous studies have documented the between-person mediating role of emotional insecurity in the link between exposure to political violence in the community and adjustment problems in adolescents (Cummings et al., 2011). The present study provides further evidence to support the cogency of emotional insecurity in the ecologically significant context of sectarian community violence in relations with youth adjustment problems. The demonstration of these relations across five waves of assessment provided a unique demonstration from a processoriented perspective of the role of youth's emotional insecurity about community in contributing to their risk for adjustment problems. Even beyond the context of understanding relations between political violence and youth adjustment, these analyses provide a rare demonstration of mediating processes from a dynamic, person-oriented perspective. 
This study thus advances empirical bases for conceptualizations of the psychological and developmental processes and contextual factors that relate to adolescent behavior problems delinquency in contexts of political violence. These results show the developmental significance of emotional insecurity about the community; adolescents who continue on a path of insecurity about community over time are at heightened risk for later adjustment problems. These findings call attention to the need for assessment over time of mediating processes to articulate the characteristics of risk processes, advancing a person-oriented analysis of emotional insecurity about the community as an explanatory process.

Demonstrating the importance of a social-ecological perspective on emotional insecurity, sectarian community violence elevated emotional insecurity about the community, which, in turn, was related to child adjustment problems. Although the mediational role of emotional insecurity about community in relation to child adjustment problems has been shown based on cross-sectional between-person tests (Cummings et al., 2010), and based on assessment of emotional security about community based on assessment at a single point in time based on longitudinal mediational model tests (Cummings et al., 2011), this is a unique demonstration of interrelations between these psychological response processes based on a within-person test of the mediating psychological process. Previous tests with between-person models allow us to look across people to identify who is most at risk for emotional insecurity and adjustment problems. The results of the current study further support the notion that emotional security is a selfregulating system that responds to an individual's changing context. The findings suggest that when each individual experiences higher levels of sectarian antisocial behavior compared to his/her average, that individual's levels of emotional security and adjustment are affected. These person-centered analyses more closely reflect developmental process. This work thus adds to the 
evidence from other longitudinal studies examining patterns of adjustment over time from a social-ecological perspective (e.g., Betancourt et al., 2014; Dubow et al., 2012), breaking new ground in advancing the longitudinal, process-oriented study of relations between political violence and youth adjustment.

On the other hand, the fact that the direct effect of SAB on youth's total adjustment problems remained significant even after the inclusion of the indirect pathway explicitly suggests that it is necessary to include additional mediating psychological processes in mediational model testing in order to fully explain youth adjustment outcomes. That is, direct relations between sectarian community violence and youth adjustment ultimately must be understood in terms of psychological processes that explain how and why these relations are obtained. The psychological processes identified by other research groups concerned with relations between political violence and armed conflict and youth adjustment provide important possible leads on the nature of the additional psychological processes that may be relevant (e.g., Betancourt et al., 2014; Dubow et al., 2009). Moreover, the results also indicate significant variability in these within-person processes suggesting that additional between-person variables should be included to examine, in addition to gender, for whom exposure to political conflict has stronger associations to emotional insecurity and for whom exposure has stronger associations to adjustment problems, and for whom emotional security has stronger associations with adjustment problems.

Moreover, although not a diagnostic outcome of psychopathology, emotional insecurity is conceptualized as a process-oriented risk factor for psychopathology that dynamically exercises influence over time in the context of other risk and protective factors in the social ecology (DeKlyen \& Greenberg, 2008). Frequent or prolonged activation of the emotional security 
regulatory system may increase the risk of adjustment problems through a variety of processes, including being highly demanding of youth’s psychological and physical resources, thereby reducing their capacities to regulate functioning in multiple social contexts or pursue developmental goals. A limitation of the present report is that both emotional insecurity and total behavior problems were based on youth self-report. On the other hand, a case can be made that youth provide a highly valuable source of information about emotional insecurity and adjustment problems.

In this instance, the findings add further cogency to the notion that youth’s emotional insecurity about community over time is a mediating process relating to their risk for adjustment problems in contexts of political violence. Notably, person-oriented theory may reflect a relatively wide variety of propositions about processes concerning holistic, transactional, and individualized processes of change over time; this study is limited to testing a specific set of propositions from a person-oriented perspective; other propositions regarding the conceptualization of person-oriented processes also merit consideration (Sterba \& Bauer, 2010). In addition, the current study does not include change over time at the within-person or autoregressive level, limiting conclusions about direction of effects. At the same time, previous between-person longitudinal studies have supported the direction of effects as implied by emotional security theory. The within-person model would benefit from future research examining change over time and auto-regressive controls. Another important direction for future research is to further test propositions derived from emotional security theory (Cummings \& Davies, 2010; Davies \& Cummings, 1994) and other theories (e.g., social identity theory; Merrilees et al., 2014) in additional contexts of historical political violence and armed conflict to advance further process-oriented, theory-driven explanatory models for youth adjustment. 
The results also suggest that ameliorating children’s insecurity about community in contexts of political violence is an important goal toward improving adolescents' well-being, including reduced risk for delinquency. Extending attachment theory (Bowlby, 1973) to other social-ecological contexts, children's emotional security about their communities as well as their families are identified as significant to youth adjustment in contexts of political violence (Cummings \& Davies, 2011). While bases for increasing security in parent-child relationships are relatively well-understood (Juffer, Bakersmans-Kranenburg, \& van IJzendoorn, 2008), a challenge for future research is to identify ways to increase children's sense of security about their communities in contexts of political violence. Especially in contexts in which political violence and armed conflict are chronic and not likely to be amenable to political resolution in the near future (e.g., the conflict in Israel and Palestine), this challenge is likely to be both significant and highly important. For communities with decades if not centuries of conflict and tension between groups, promoting security and trust in group relations will especially difficult. Relatedly, the development and testing of cost-effective interventions for increasing emotional security about the community in these contexts is an important goal for future research. Addressing multiple levels of the social ecology, children's emotional security may be advanced by programs to increase both support in schools/community (Slone, Shoashni \& Lobel, 2013) and parent-child communication (Dybdahl, 2001). At the same time, it is likely important to increase the security of contexts that are most proximal to children’s functioning (e.g., the family) for optimal support of child development in these contexts (Heberle, Thomas, Wagmiller, Briggs-Gowan, \& Carter, 2014).

Although numerous efforts have been made to develop programs to foster the well-being and mental health of children in contexts of political violence and armed conflict, in most cases 
the programs have not been evaluated or met even minimal criteria of presentation of scientific evidence on program efficacy (Betancourt, Meyers-Ohki, Charrow, \& Tol, 2013; Jordans, Tol, Komproe, \& de Jong, 2009). However, even among the programs subjected to published tests of empirical validation, there is little systematic basis reported in basic research on the impact of political violence and armed conflict on children incorporated into the development of program content or testing of theoretical models about why programs may work or possible mediators or moderators concerning why programs were, or were not, effective. There is an emerging consensus that the evidence base for prevention and intervention approaches needs to be strengthened (National Advisory Mental Health Council, 2000) and that more emphasis needs to be placed on family and community-based interventions (Betancourt et al., 2013), which are extensively documented as vitally important areas of the social ecology for child functioning in basic research studies, including the findings presented in the present report and elsewhere in this Special Section (e.g., Huesmann et al.).

Longitudinal, process-oriented work provide especially informative bases for translational research. The aim of translational research is to create close connections between basic research and its applications to mental and physical health outcomes (Cicchetti \& Toth, 2006). The National Institutes of Mental Health has put forth a roadmap emphasizing the critical need for basic research discoveries to be applied towards the development of more effective treatment and prevention models (National Advisory Mental Health Council, 2000; Zerhouni, 2003; see also Gunnar \& Cicchetti, 2009). From a developmental psychopathology perspective, a critical next step for results based on advanced longitudinal research designs for identifying explanatory processes for child adjustment is to translate these findings into the context of prevention and intervention programs. 
Currently, relatively few studies are evident that optimally support the efficacy of prevention and intervention programs, including foundations in well-articulated theory and translation of basic research findings into program content. There is an emerging consensus that the evidence base for prevention and intervention approaches needs to be strengthened, including a dismantling of what works and why, and more emphasis placed on family- and communitybased interventions (Betancourt et al., 2013), which are extensively documented as vitally important areas of the social ecology for child functioning.

Intervention research should ideally be guided by both findings from basic research and theoretical models for change, including explicit tests of theoretical change models. The present findings add to evidence for the cogency of EST as a theoretical model for intervention based on a process-oriented, social-ecological perspective. Building on attachment theory and research (Bowlby, 1973; DeKlyen \& Greenberg, 2008), the present study complements findings of other studies in Northern Ireland suggesting that children's emotional security about both the family (Cummings et al., 2012) and community, and family and community considered together (Cummings et al., in press), relates to children's adjustment in contexts of political violence. Therefore, there is a foundation for a social-ecological model of EST as a potential theoretical model for change based on tests of explanatory mechanisms for developmental change in Northern Ireland. In outline, this direction would involve providing contexts through intervention programs for increasing children's sense of safety and security in multiple social-ecological contexts. Finally, EST has received empirical support as a theory of change model for intervention in USA contexts (e.g., Miller-Graff, Cummings \& Bergman, in press).

In closing, an ecological framework based on multilevel approaches to intervention, including at the level of the family, may hold particular promise for substantial and long-term 
improvements in understanding and intervening for the sake of children's psychological wellbeing and adjustment in contexts of political violence and armed conflict (Betancourt et al. 2013). Accordingly, an important next step is the conduct of translational research (Cicchetti \& Toth, 2006) that systematically incorporates process-oriented, social-ecological findings derived from the body pf prospective research on the factors that relate to child outcomes into the development of more efficacious and effective prevention and intervention programs. 


\section{References}

Achenbach, T. M. (1991). Manual for the Child Behavior Checklist/4-18 and 1991 Profile.

Burlington, VT: University of Vermont, Department of Psychiatry.

Bauer, D. J., Preacher, K. J., \& Gil, K. M. (2006). Conceptualizing and testing random indirect effects and moderated mediation in multilevel models: New procedures and recommendations. Psychological Methods, 11(2), 142-163.

doi:http://dx.doi.org/10.1037/1082-989X.11.2.142

Bergman, L. R., von Eye, A., \& Magnusson, D. (2006). Person-oriented research strategies in developmental psychopathology. (pp. 850-888) John Wiley \& Sons Inc, Hoboken, NJ.

Betancourt, T. S., Borisova, I., Williams, T. P., Meyers-Ohki, S. E., Rubin-Smith, J. E., Annan, J., \& Kohrt, B. A. (2013). Research review: Psychosocial adjustment and mental health in former child soldiers - A systematic review of the literature and recommendations for future research. Journal of Child Psychology and Psychiatry, 54(1), 17-36. doi: 10.1111/j.1469-7610.2012.02620.x

Betancourt, T. S., Brennan, R. T., Rubin-Smith, J., Fitzmaurice, G. M., \& Gilman, S. E. (2010). Sierra leone's former child soldiers: A longitudinal study of risk, protective factors and mental health. Journal of the American Academy of Child \& Adolescent Psychiatry, 49(6), 606-615. doi:http://dx.doi.org/10.1097/00004583-201006000-00009

Bollen, K. A. (1989). Structural equations with latent variables John Wiley \& Sons, Oxford. Bowlby, J. (1973). Attachment and Loss: Volume II: Separation, Anxiety and Anger: London: The Hogarth Press and the Institute of Psycho-Analysis. 1-429.

Boxer, P., Huesmann, R.L., Dubow, E.F., Landau, S.F., Gvirsman, S.D., Shikaki, K., \& Ginges, J. (2013). Exposure to violence across the social ecosystem and the development of 
aggression: A test of ecological theory in the Israeli-Palestinian conflict. Child Development, 84 (1), 163-177. doi: 10.1111/j.1467-8624.2012.01848.x

Browning, C. R., Burrington, L. A., Leventhal, T., \& Brooks-Gunn, J. (2008). Neighborhood structural inequality, collective efficacy, and sexual risk behavior among urban youth. Journal of Health and Social Behavior, 49(3), 269-285. doi:http://dx.doi.org/10.1177/002214650804900303

Cairns, E. (1987). Caught in the crossfire: Children and the Northern Ireland conflict. Appletree Press, Belfast.

Cairns, E. (1996). Children and Political Violence. Oxford: England: Blackwell.

Cairns, E., \& Darby, J. (1998). The conflict in Northern Ireland: Causes, consequences, and controls. American Psychologist, 53(7), 754-760. doi:http://dx.doi.org/10.1037/0003066X.53.7.754

Cairns, E., \& Toner, I. J. (1993). Children and political violence in Northern Ireland: From riots to reconciliation. The Psychological Effects of War and Violence on Children. (pp. 215229) Lawrence Erlbaum Associates, Inc, Hillsdale, NJ.

Cicchetti, D. (2006). Development and psychopathology. In D. Cicchetti \& D. J. Cohen (Ed.), Developmental Psychopathology: Vol. 1. Theory and methods (pp.1-23). New York: Wiley.

Cicchetti, D., \& Cohen, D. J. (1995). Perspectives on developmental psychopathology. In D. Cicchetti \& D. J. Cohen (Ed.), Developmental psychopathology: Vol. 1. Theory and methods (pp. 3-22). New York: Wiley.

Cicchetti, D., \& Lynch, M. (1993). Toward an ecological/transactional model of community 
violence and child maltreatment: Consequences for children’s development. Psychiatry, 56, 96-118.

Cicchetti, D., \& Toth, S. L. (2006). Building bridges and crossing them: Translational research in developmental psychopathology. Development and Psychopathology, 18, 619-622. doi: 10.1017/S0954579406060317

Cicchetti, D., \& Valentino, K. (2006). An ecological-transactional perspective on child maltreatment: Failure of the average expectable environment and its influence on child development (pp. 129-201). Hoboken, NJ, US: John Wiley \& Sons Inc, Hoboken, NJ.

Cummings, E. M., \& Davies, P. T. (2011). Marital conflict and children: An emotional security perspective. New York and London: The Guilford Press.

Cummings, E. M., Goeke-Morey, M. C., Schermerhorn, A. C., Merrilees, C. E., \& Cairns, E. (2009). Children and political violence from a social ecological perspective: Implications for research on children and families in Northern Ireland. Clinical Child and Family Psychology Review, 12, 16-38

Cummings, E. M., Goeke-Morey, M., Merrilees, C. E., Taylor, L. K., Shirlow, P. A. (2014). Social-ecological, process-oriented perspective on political violence and child development. Child Development Perspectives. 12(1): 16-38.

Cummings, E. M., Merrilees, C.E., Schermerhorn, A.C., Goeke-Morey, M. C., Shirlow, P., \& Cairns, E. (2011). Longitudinal pathways between political violence and child adjustment: The role of emotional security about the community in Northern Ireland. Journal of Abnormal Child Psychology, 39, 213-224.

Cummings, E. M., Merrilees, C. E., Schermerhorn, A. C., Goeke-Morey, M. C., Shirlow, P., \& 
Cairns, E. (2012). Political violence and child adjustment: Longitudinal tests of sectarian antisocial behavior, family conflict and insecurity as explanatory pathways. Child Development, 83, 461-468. doi: 10.1111/j.1467-8624.2011.01720.x

Cummings, E. M., Davies, P., \& Simpson, K. (1994). Marital conflict, gender, and children's appraisal and coping efficacy as mediators of child adjustment. Journal of Family Psychology, 8, 141-149.

Cummings, E. M., Schermerhorn, A. C., Merrilees, C. M., Goeke-Morey, M. C., \& Cairns, E. (2010). Political violence and child adjustment in Northern Ireland: Testing pathways in a social ecological model including single- and two-parent families. Developmental Psychology, 46, 827-841.

Cummings, E. M., Taylor, L. K., Merrilees, C. E., Goeke-Morey, M. C., \& Shirlow, P. (in press). Emotional insecurity in the family and community and youth delinquency in Northern Ireland: A person-oriented analysis across five-waves. Journal of Child Psychology and Psychiatry.

Cummings, E. M., \& Valentino, K. V. (2015). Development Psychopathology. In W. F. Overton \& P. C. M. Molenaar (Eds.) Theory and Method. Volume 1 of the Handbook of child psychology and developmental science. (7th ed.) (pp. 566-606). Editor-in-Chief: Richard M. Lerner. Hoboken, NJ: Wiley.

Davies, P. T., \& Cummings, E. M. (1994). Marital conflict and child adjustment: An emotional security hypothesis. Psychological Bulletin, 116, 387-411.

Davies, P. T., Forman, E. M., Rasi, J. A., \& Stevens, K. I. (2002). Assessing Children’s Emotional Security in the Interparental Relationship: The Security in the Interparental Subsystem Scales. Child Development, 73(2), 544-562. doi:10.1111/1467-8624.00423 
DeKlyen, M., \& Greenberg, M. T. (2008). Attachment and psychopathology in childhood Guilford Press, New York, NY.

Dubow, E.F., Huesmann, L.R., \& Boxer, P. (2009). A social-cognitive-ecological framework for understanding the impact of exposure to persistent ethnic-political violence on children’s psychosocial adjustment. Clinical Child and Family Psychology Review, 12(2), 113-126. doi: 10.1007/s10567-009-0050-7

Dybdahl, R. (2001). Children and mothers in war: An outcome study of a psychosocial intervention program. Child Development, 72, 1214-1230.

Davies, P. T., Forman, E. M., Rasi, J. A., \& Stevens, K. I. (2002). Assessing Children’s Emotional Security in the Interparental Relationship: The Security in the Interparental Subsystem Scales. Child Development, 73(2), 544-562. doi:10.1111/1467-8624.00423

Goeke-Morey, M. C., Cummings, E. M., Ellis, K., Merrilees, C. E., Schermerhonrn, A. C., Shirlow, P., \& Cairns, E. (2009). The differential impact on children of inter- and intracommunity violence in Northern Ireland. Peace and Conflict: Journal of Peace Psychology, 15, 367-383.

Goodman, R. (1997). The strengths and difficulties questionnaire: A research note. Child Psychology \& Psychiatry \& Allied Disciplines, 38(5), 581-586.

Goodman, R., \& Scott, S. (1999). Comparing the strengths and difficulties questionnaire and the child behavior checklist: Is small beautiful? Journal of Abnormal Child Psychology, 27(1), 17-24.

Gunnar, M. R., \& Cicchetti, D. (2009). Meeting the challenge of translational research in child psychology. In M. R. Gunnar \& D. Cicchetti (Eds.) Meeting the Challenge of Translational Research in Child Psychology: Minnesota Symposia on Child Psychology 
(Vol. 35, pp. 1-27). New York: Wiley.

Heberle, A.E., Thomas, Y.M., Wagmiller, R.L., Briggs-Gowan, M.J., \& Carter,A.S. (2014). The impact of neighborhood, family and individual risk factors on toddlers' disruptive behavior. Child Development, 85 (5), 2046-2061

Hughes, J., Campell, A., Hewstone, M., \& Cairns, E. (2007). Segregation in Northern IrelandImplications for community relations policy. Policy Studies, 28, 33-53. doi: $10.1080 / 0144287061121429$

Juffer, F., Bakermans-Kranenburg, M., \& van IJzendoorn, M. H. (2008). Promoting positive parenting: An introduction.Promoting positive parenting: An attachment-based intervention. (pp. 1-9) Taylor \& Francis Group/Lawrence Erlbaum Associates, New York, NY.

Kronenberg, M. E., Hansel, T. C., Brennan, A. M., Osofsky, H. J., Osofsky, J. D., \& Lawrason, B. (2010). Children of Katrina: Lessons learned about postdisaster symptoms and recovery patterns. Child Development, 81, 1241-1259.

Lynch, M., \& Cicchetti, D. (1998). An ecological-transactional analysis of children and contexts: The longitudinal interplay among child maltreatment, community violence, and children’s symptomatology. Development and Psychopathology, 10, 235-257.

Masten, A. S., \& Narayan, A.J. (2012). Child development in the context of disaster, war, and terrorism: Pathways of risk and resilience. Annual Review of Psychology 63, 227-257. doi: 10.1146/annurev-psych-120710-10035

Merrilees, C. E., Taylor, L. K., Goeke-Morey, M. C., Shirlow, P. Cummings, E. M. (2014). Youth in contexts of political violence: A developmental approach to the study of youth 
identity and emotional security in their communities. Peace and Conflict: Journal of Peace Psychology. 20 (1), 26-39

Miller-Graff, L. Cummings, E. M., and Bergman, K. N. (in press). Effects of a Brief Psychoeducational Intervention for Family Conflict: Constructive Conflict, Emotional Insecurity and Child Adjustment. Journal of Abnormal Child Psychology.

National Advisory Mental Health Council (2000). Translating behavioral science into action: Report of the National Advisory Mental Health Council's behavioral science workgroup (no. 00-4699). Bethesda, MD: National Institutes of Mental Health.

Nesselroade, J. R., \& Molenaar, P. C. M. (2010). Emphasizing intraindividual variability in the study of development over the life span: Concepts and issues. John Wiley \& Sons Inc, Hoboken, NJ. doi:http://dx.doi.org/10.1002/9780470880166.hlsd001002

Northern Ireland Statistics \& Research Agency, Northern Ireland Neighbourhood Information Service. (2011). NINIS Data Catalogue. Retrieved from http://www.ninis.nisra.gov.uk/mapxtreme/DataCatalogue.asp?button=Crime

Police Service of Northern Ireland. (2013). Police reported crime in Northern Ireland. Retrieved from http://www.ninis2.nisra.gov.uk/public/Theme.aspx?themeNumber=131\&theme Name $1 \frac{1}{4}$ CrimepandpJustice

Raudenbush, S. W., Bryk, A. S., Cheong, Y. F., \& Congdon, R. T. (2004). HLM 6: Hierarchical linear and nonlinear modeling. Chicago, IL: Scientific Software International.

Shirlow, P., \& Murtagh, B. (2006). Belfast: Segregation, violence and the city. London, England: Pluto Press. 
Slone, M., Shoshani, \& Lobel (2013). Helping youth immediately following war exposure: A randomized controlled trial of a school-based intervention program. Journal of Primary Prevention, 34, 293-307.

Sterba, S. K., \& Bauer, D. J. (2010). Statistically evaluating person-oriented principles revisited. Development and Psychopathology, 22(2), 287-294. doi:http://dx.doi.org/10.1017/S0954579410000064

Taylor, L.K., Merrilees, C.E., Campbell, A., Shirlow, P., Cairns, E., Goeke-Morey, M.C., Schermerhorn, A.C., \& Cummings, E.M. (2011). Sectarian and Nonsectarian Violence: Mothers’ Appraisals of Political Conflict in Northern Ireland. Peace and Conflict: Journal of Peace Psychology, 17, 343-366.

United Nations. (2011). United Nations Children's Fund. State of the World's Children. Retrieved from http://www.unicef.org/sowc2011/ pdfs/SOWC-2011-ExecutiveSummary-LoRes_EN_12132010.pdf

Zerhouni, E. (2003). The NIH roadmap. Science, 302(5642), 63-72. doi: 10.1126/science.1091867 


\section{Figure Captions}

Figure 1. The Indirect Effect of Emotional Insecurity in the Community in Mediating the Effects of Sectarian Antisocial Behavior on Youth Total Adjustment Problems

Figure 2. Child Gender as a Moderator of Relations between Sectarian Antisocial Behavior and Emotional Insecurity in the Community 


$$
\begin{aligned}
& Y=.12, \text { S. E. }=.02, p< \\
& .001 ; \operatorname{var}=.03, p< \\
& .001
\end{aligned}
$$

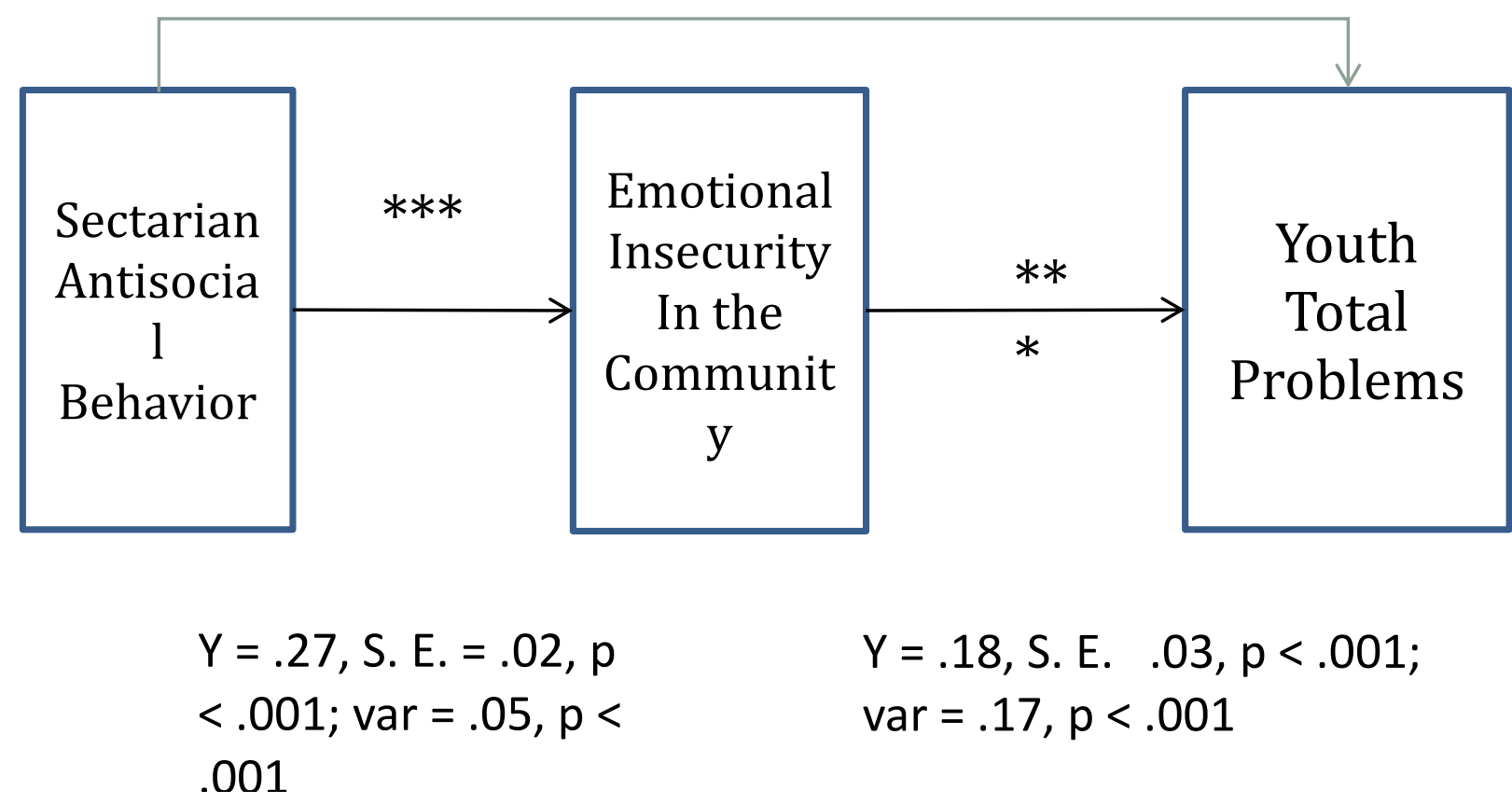




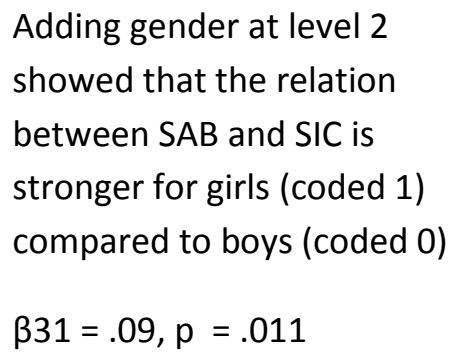

\begin{tabular}{|c|c|c|c|c|}
\hline Sectarian & $* * *$ & $\begin{array}{l}\text { Emotional } \\
\text { Insecurity }\end{array}$ & $* *$ & Youth Total \\
\hline Behavior & & $\begin{array}{l}\text { In the } \\
\text { Community }\end{array}$ & & ems \\
\hline
\end{tabular}

$$
\begin{array}{ll}
Y=.27, \text { S. E. }=.02, p<.001 ; & Y=.18, \text { S. E. .03, } p<.001 ; \\
\text { var }=.05, p<.001 & \text { var }=.17, p<.001
\end{array}
$$

